\title{
Empleo del colgajo muscular extensor digitorum brevis con flujo retrógrado para defectos distales en el pie
}

\section{Use of reverse flow extensor digitorum brevis muscle flap for distal foot defects}

\author{
De Lope Falcón, C.*, Lagares Borrego, A.*, Barrera Pulido, F.J .*, \\ Sicilia Castro, D*, Gómez Cía.**
}

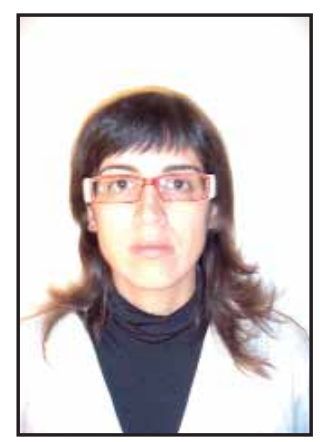

De Lope Falcón, C.

\section{Resumen}

Los colgajos en isla con vascularización distal y, entre ellos, el colgajo muscular Extensor Digitorum Brevis, son en la actualidad una opción excelente para conseguir la cobertura satisfactoria de los defectos de tejidos blandos a nivel del dorso del pie y de los dedos. En este artículo revisamos casos publicados por otros autores de defectos distales del pie, resueltos mediante este colgajo muscular, así como estudios anatómicos sobre la vascularización del mismo y presentamos 2 casos intervenidos en nuestro Servicio en los que obtuvimos una cobertura satisfactoria y una pronta recuperación, sin complicaciones vasculares, morbilidad de la zona donante o limitación funcional; solo una hipoestesia persistente a nivel del dorso del pie.

$\begin{array}{ll}\text { Palabras clave } & \begin{array}{l}\text { Músculo Extensor Digitorum Brevis. } \\ \text { Defectos del dorso del pie. Colgajos con } \\ \text { vascularización distal. }\end{array} \\ \text { Código numérico } & 158332-4134\end{array}$

$\begin{array}{ll}\text { Key words } & \begin{array}{l}\text { Extensor Digitorum Brevis muscle. Dis- } \\ \text { tal foot defect. Reverse-flow flap. }\end{array} \\ \text { Numeral Code } & 158332-4134\end{array}$

Island flaps with distal vascularization, including Extensor Digitorum Brevis flap, are an excellent choice for achieving satisfactory coverage of soft tissues defects at the back of the feet and fingers. In this article we review the use of this flap by other authors in distal foot defect and the anatomical studies about its vascularization. We report 2 cases operated on our Department of Plastic Surgery with distal foot defects solved with this flap. We obtained a satisfactory coverage and a speedy recovery. No vascular complications, morbidity of the donor site or functional limitation were noticed. The only complaint was persistent hypoaesthesia on the back foot.

\footnotetext{
* Especialista en Cirugía Plástica, Estética y Reparadora. 


\section{Introducción}

Obtener una cobertura satisfactoria de los defectos de partes blandas de la región distal del pie continúa siendo un problema difícil de resolver. En la literatura al respecto, encontramos diferentes colgajos locales como son: el colgajo fileteado de un dedo del pie, descrito por Emmett, que permite cubrir defectos distales pero presenta la desventaja del sacrificio de un dedo; el colgajo del primer espacio intermetatarsiano dorsal; el colgajo en isla de arteria pedia dorsal pediculado distalmente, con una morbilidad importante de la zona donante y un arco de rotación escaso; el colgajo fasciograso turn-over, propuesto por Lai, que requiere un pedículo muy largo, por lo que su uso en el dorso del pie es limitado y los colgajos venosos o colgajos venosos arterializados, que resultan una opción reconstructiva interesante, pero que desafortunadamente no siempre están disponibles.

El colgajo del músculo Extensor Digitorum Brevis (EDB) ha sido ampliamente usado como colgajo en isla con flujo anterógrado, para cubrir defectos del tercio inferior de la pierna y del tobillo, con el consiguiente sacrificio de uno de los ejes vasculares del pie (1). Kurata y Soyka (2) describieron el colgajo con flujo retrógrado para la cobertura de los defectos distales del dorso del pie; más recientemente, se ha presentado su uso como colgajo libre, que permite el cierre de pequeños defectos yuna reconstrucción funcional de determinadas lesiones (3).

\section{Material y método}

\section{Recuerdo anatómico}

El músculo EDB es un músculo corto, grueso y carnoso situado sobre la cara dorsal del pie, debajo de los tendones del músculo extensor largo de los dedos. Se extiende desde el calcáneo hasta los cuatro primeros dedos, dividiéndose en cuatro haces, de los cuales, el más medial se fija en la base de la primera falange del primer dedo y el resto se unen al tendón correspondiente del extensor largo de los dedos. Su vascularización está asegurada por la arteria tarsiana lateral, rama de división de la arteria pedia, que alcanza el músculo por su borde medial y está considerada como la arteria principal del músculo (3). Como segunda arteria se encuentra, de manera constante, la arteria perforante peronea que se anastomosa con la tarsiana lateral (4). Dependiendo del estudio anatómico consultado, además existen de 1 a 3 pedículos accesorios procedentes de la arteria pedia dorsal, generalmente distales al origen de la arteria tarsiana lateral (1).

El músculo está inervado por una rama del nervio peroneo profundo que acompaña a la arteria principal.
La arteria pedia dorsal es la continuación de la arteria tibial anterior; entra en el pie bajo el retinaculum extensor, cruza el dorso del pie hacia el primer espacio intermetatarsiano, medialmente al músculo EDB. En el borde inferior del retinaculum extensor o inmediatamente por debajo de él tiene su origen la arteria tarsiana lateral y $2 \mathrm{~cm}$ por debajo del mismo, da la arteria tarsiana medial que se une con la arteria plantar medial. $\mathrm{La}$ arteria pedia dorsal alcanza el primer espacio intermetatarsiano y da la primera arteria metatarsiana dorsal, que desciende y se anastomosa con el arco plantar. Un par de venas comitantes y sus ramas proporcionan el retorno venoso. Aunque la anatomía puede verse modificada, las anastomosis entre el sistema vascular dorsal y plantar son constantes (Fig. 1).

La vascularización del primer espacio intermetatarsiano es variable; están descritos 3 tipos en relación al músculo interóseo $(5,6)$ :

Tipo I: La arteria es superficial al músculo interóseo $(66 \%)$.

Tipo II: La arteria está en una situación profunda en el primer espacio (22\%).

Tipo III: La arteria rápidamente se ramifica en una rica red vascular que se comunica con el sistema plan$\operatorname{tar}(12 \%)$.

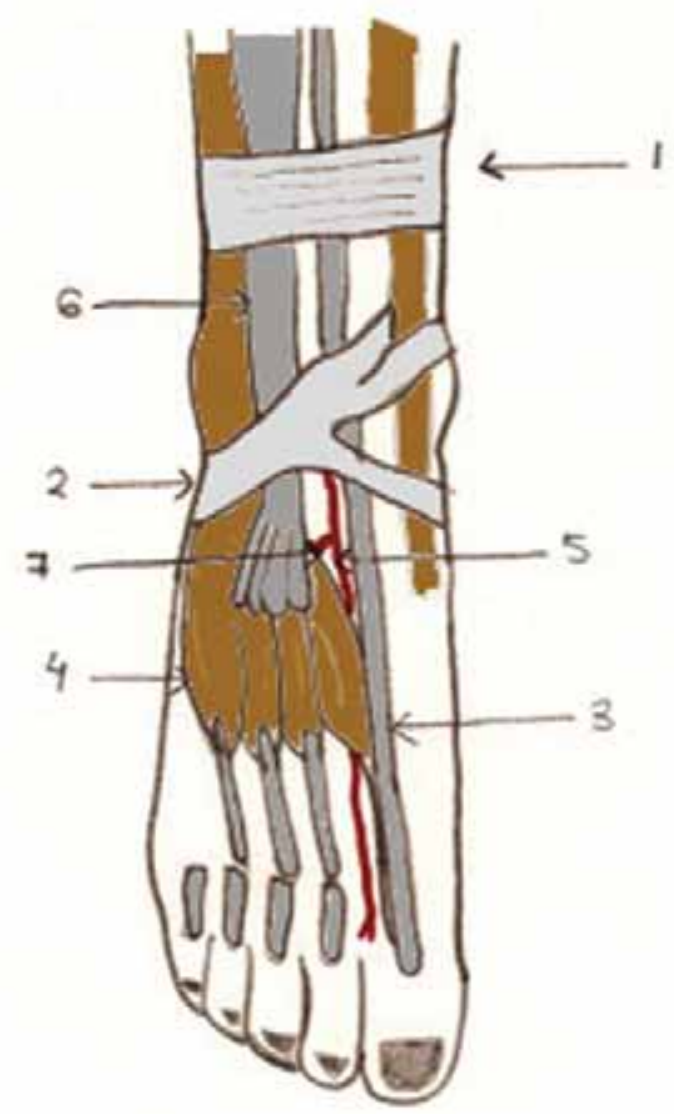

Fig. 1: Anatomía. 1: Retináculo superior de los músculos extensores; 2: Retináculo inferior de los músculos extensores; 3: Tendón del músculo extensor largo del dedo gordo; 4: Extensor corto de los dedos; 5: Arteria pedia; 6: Extensor largo de los dedos; 7: Arteria tarsiana lateral. 
Hay que tener en cuenta tres observaciones anatómicas en lo referente a la vascularización del colgajo: $(6,7)$

1) La existencia de una rama anastomótica constante entre las arterias tarsiana medial y plantar medial sobre el borde medial del pie, que permite el uso del colgajo muscular EDB incluso cuando la arteria pedia dorsal ha sido interrumpida distalmente. En este caso el colgajo pasa a denominarse Colgajo muscular EDB basado medialmente.

2) La existencia de comunicaciones vasculares adicionales entre las arterias metatarsiana dorsal y plantar del $1^{\circ}$ espacio intermetatarsiano que se localizan en el borde distal del $1^{\circ}$ espacio, proporcionando un flujo arterial retrógrado para el colgajo y permitiendo prolongar la disección del pedículo distal. El arco de rotación aumenta considerablemente y el colgajo EDB puede fácilmente alcanzar defectos muy distales del pie, de los dedos e incluso de la región plantar. En este otro caso el colgajo pasa a denominarse Colgajo muscular EDB basado muy distalmente. Para la realización del colgajo EDB con flujo reverso basado muy distalmente se consideran dos puntos pivotes (Fig. 2): uno proximal a la primera articulación tarsometatarsiana y otro distal, a nivel del primer espacio interdigital, que se puede considerar cuando la arteria metatarsiana dorsal se anastomosa con el sistema arterial plantar justo distal a la primera articulación metatarsofalángica. Si usamos este último punto pivote, hemos de confirmar la existencia de una vena comitante de la primera arteria metatarsiana dorsal. El punto pivote proximal existe en todos los casos, sin anomalía anatómica, no así el distal. Sin embargo, el arco de rotación del colgajo con punto pivote proximal es lo suficientemente grande para cubrir la mayor parte de los defectos distales del pie, excepto para la cobertura de defectos laterales del quinto dedo (8).

3) La existencia de una vascularización arterial lateral procedente de la arteria perforante peronea que se anastomosa con la arteria tarsiana lateral por debajo del músculo y que nos permite basar el colgajo en este pedículo sin sacrificar el eje tibial anterior (9).

\section{Técnica quirúrgica}

El paciente se coloca en decúbito supino y la intervención se desarrolla bajo isquemia de la extremidad, sin expresión, para facilitar la disección. Comenzamos una incisión cutánea en forma de $\mathrm{S}$ sobre el dorso del pie, siguiendo el eje de la arteria pedia dorsal del pie, desde el origen del músculo EDB hasta el primer espacio intermetartasiano. A continuación, reclinamos la piel, siempre con cuidado de no lesionar las ramas sensitivas del nervio peroneo profundo, lo que provocaría una hipoestesia algo molesta de la zona.

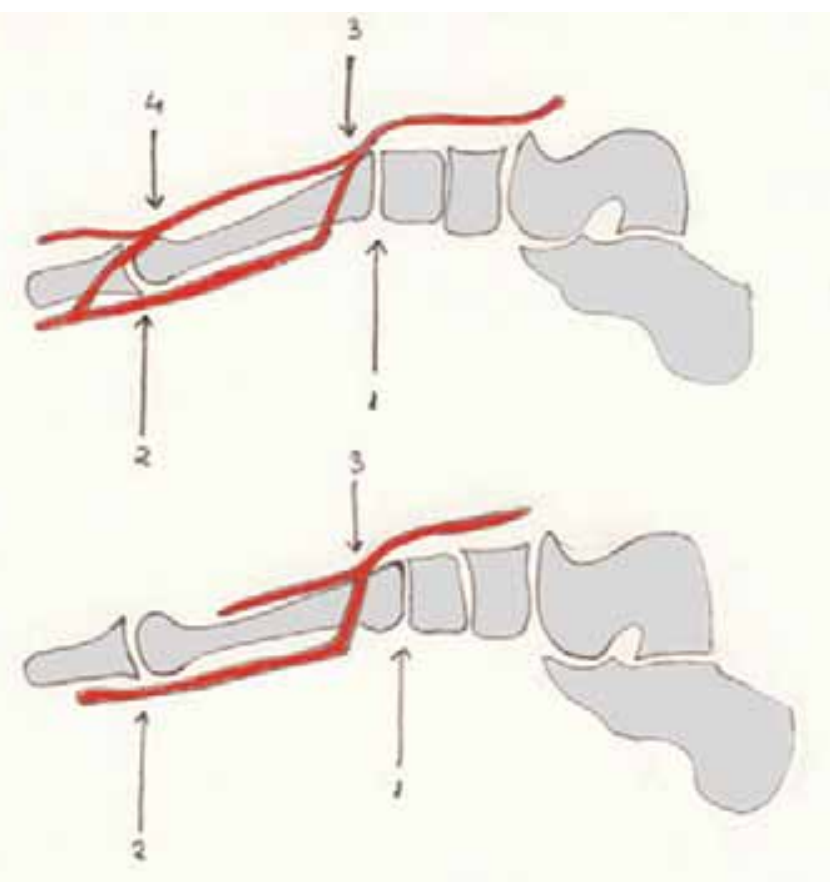

Fig. 2. Hay dos puntos pivotes para este colgajo en la mayoría de los casos, pero en algunos el punto pivote distal no existe. 1: Articulación tarsometatarsiana; 2: Articulación metatarsofalángica; 3: Punto pivote proximal; 4: Punto pivote distal.

Retraemos los tendones de los músculos extensores largos de los dedos medial y lateralmente para exponer el músculo EDB y su pedículo. Debemos identificar la arteria pedia dorsal, la arteria tarsiana lateral, la arteria tarsiana medial y la arteria del primer espacio intermetatarsiano dorsal o arteria metatarsiana. Desinsertamos el músculo de su inserción proximal sobre el calcáneo y ligamos la arteria pedia dorsal antes del nacimiento del pedículo del músculo EDB.

La disección continúa de proximal a distal en función del colgajo planificado y de la localización del defecto a cubrir. Si el colgajo es de base medial, retraemos medialmente el tendón del músculo extensor largo del dedo gordo y exponemos los vasos tarsianos mediales; el pedículo se diseca hacia abajo, tomando como referencia el músculo abductor del dedo gordo, sobre el borde medial del pie. Este colgajo se vasculariza por las anastomosis existentes entre la arteria tarsiana medial dorsal y la arteria medial plantar. Si el colgajo es de base muy distal, debemos ligar los vasos tarsianos mediales y el arco metatarsiano dorsal y podemos pedicular el colgajo en los dos puntos pivotes, proximal o distal, que hemos comentado antes. Cuando queremos pedicular el colgajo en su punto pivote más distal, disecamos todo el pedículo metatarsiano. Cuando la vascularización de este primer espacio es de tipo I, junto al pedículo vascular debemos incluir la fascia del músculo interóseo dorsal; si es de tipo II, incluiremos una porción del músculo interóseo en el pedículo; y si es de tipo III, la 


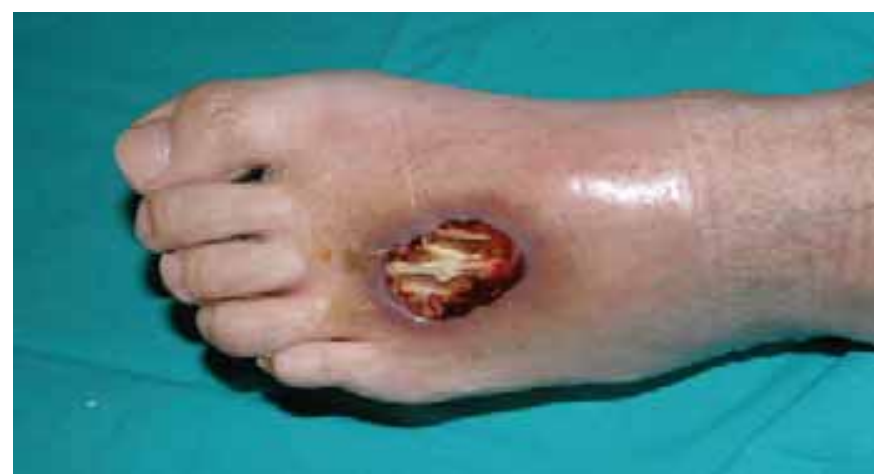

Fig. 3: Varón de 23 años con pérdida de sustancia en dorso de pie izquierdo secundaria a sepsis por $\mathrm{E}$. Coli.

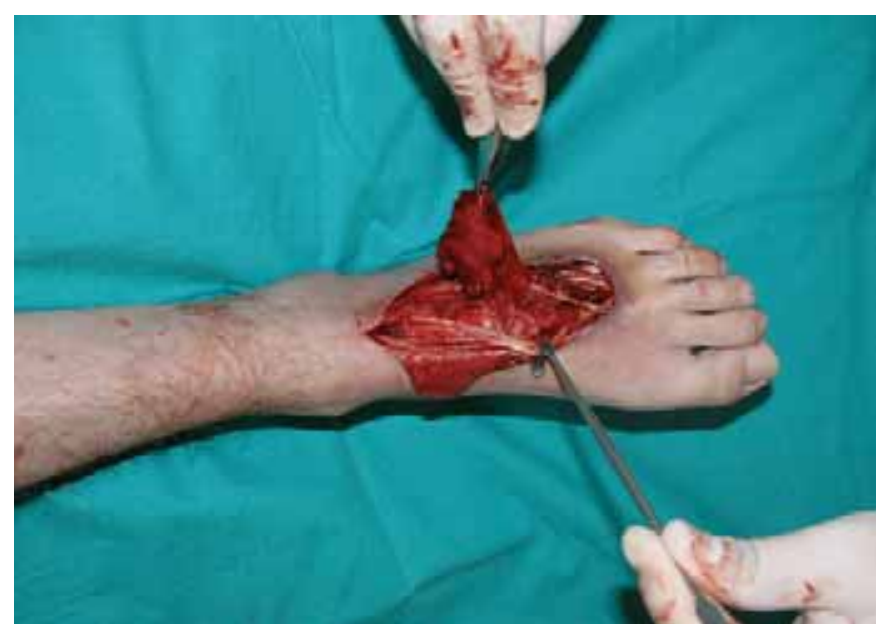

Fig. 4: Colgajo muscular EDB con flujo retrógrado basado en la primera arteria metatarsiana dorsal.

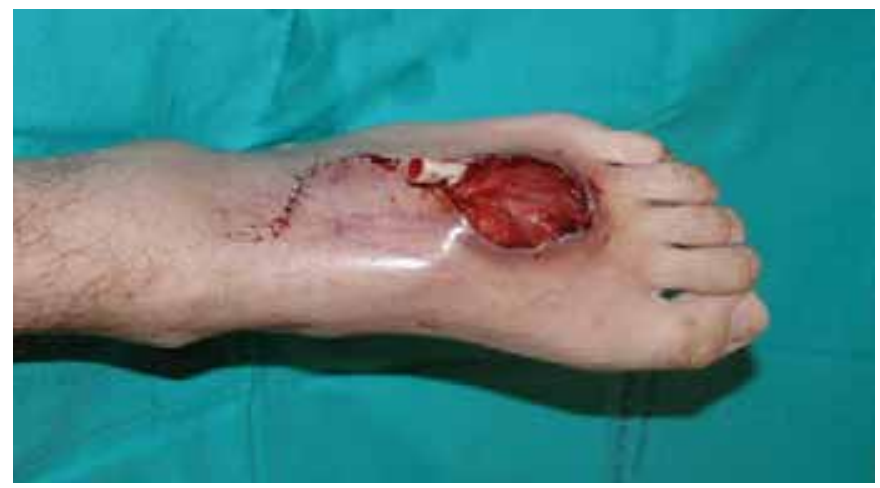

Fig. 5: Colgajo en posición.

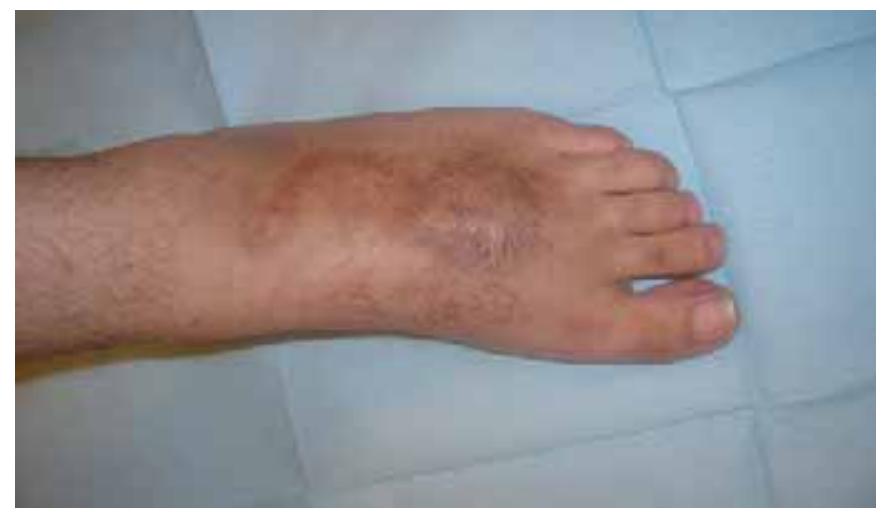

Fig. 6: Resultado postoperatorio a los 6 meses. disección debe ser igual a la del tipo II $(6,7)$. No debemos olvidar confirmar la existencia de una vena comitante de la primera arteria metatarsiana dorsal.

En nuestra experiencia, una de las cuestiones más importantes es la localización de la incisión cutánea. Debemos realizarla lateral a la arteria pedia, para asegurar que la vascularización cutánea de la región medial del pie se conserve por ramas de la arteria peronea, de lo contrario corremos serio riesgo de necrosis.

\section{Casos clínicos}

Caso 1: Colgajo muscular de EDB basado distalmente con punto pivote proximal

Varón de 23 años de edad diagnosticado de leucemia linfoblástica aguda (subtipo L1FAB) y en tratamiento con quimioterapia. Presenta pérdida de sustancia en el dorso del pie izquierdo, a nivel de $3^{\circ}$ y $4^{\circ}$ metatarsianos, con exposición de los tendones extensores largos y cortos de los dedos de los pies secundaria a necrosis cutánea por sepsis por E. Coli. (Fig. 3).

Bajo anestesia general se procede a desbridamiento del defecto y cobertura mediante colgajo muscular de EDB con flujo retrógrado basado en la $1^{\mathrm{a}}$ arteria metatarsiana dorsal, justificado por la anastomosis que existe entre esta arteria y el sistema plantar a nivel de la $1^{\mathrm{a}}$ articulación tarsometatarsiana. (Fig. 4, 5) El colgajo se recubre con un fino autoinjerto de piel parcial (Fig. 6).

\section{Caso 2: Colgajo muscular de EDB basado distal- mente con punto pivote proximal}

Mujer de 63 años de edad intervenida por neuroma de Morton en $4^{\circ}$ dedo del pie izquierdo. Presenta pérdida de sustancia, de 3 meses de evolución, en dorso de dicho pie, a nivel del $4^{\circ}$ metatarsiano, con exposición del tendón extensor largo del $4^{\circ}$ dedo, secundaria a necrosis cutánea posthematoma acontecido en el postoperatorio inmediato. La paciente ya había sufrido dos intentos fallidos de cierre por primera intención (Fig. 7).

Bajo anestesia general, se procede a Friedrich del defecto y cierre mediante colgajo muscular de EDB con flujo retrógrado basado en la $1^{\mathrm{a}}$ arteria metatarsiana dorsal, justificado por la anastomosis que existe entre esta arteria y el sistema plantar a nivel de la $1^{\mathrm{a}}$ articulación tarsometatarsiana. La vascularización a nivel del primer espacio intermetatarsiano es de tipo I (Fig. 8-10).

Resultados

Ambos colgajos sobrevivieron. No apareció ninguna complicación ni en los colgajos ni en las zonas 


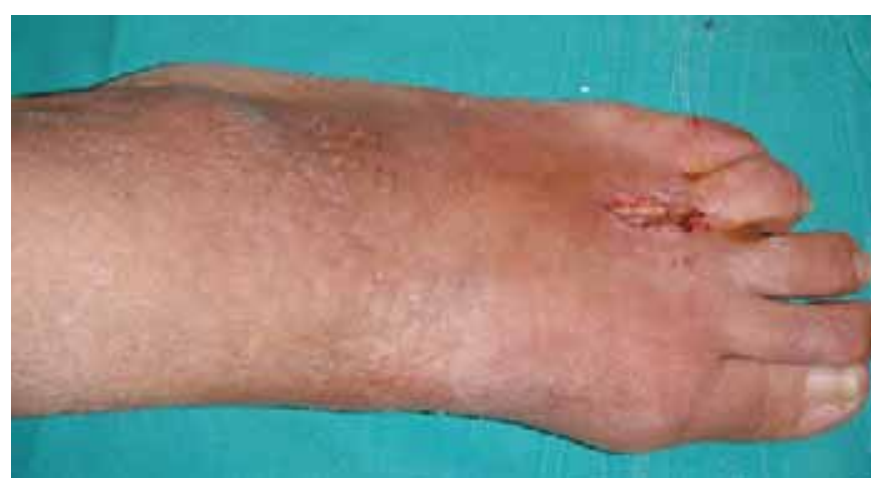

Fig. 7: Mujer de 63 años con pérdida de sustancia de 3 meses de evolución secundaria a necrosis cutánea posthematoma en postoperatorio inmediato de neuroma de Morton.

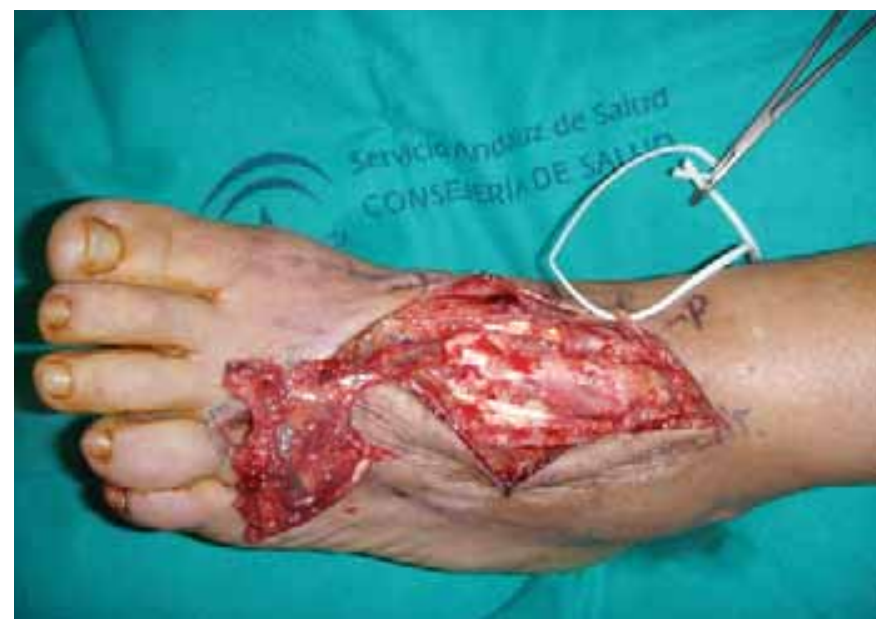

Fig. 8: Colgajo muscular EDB con flujo retrógrado basado en la primera arteria metatarsiana dorsal.

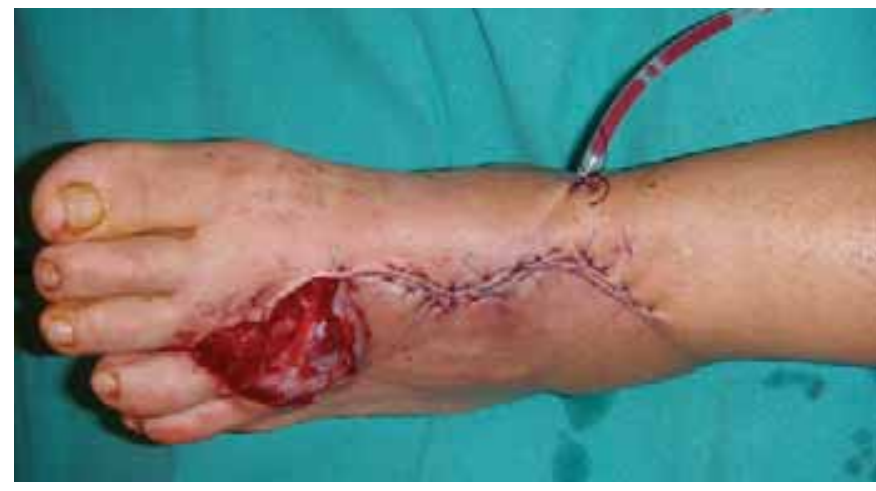

Fig. 9: Colgajo en posición.

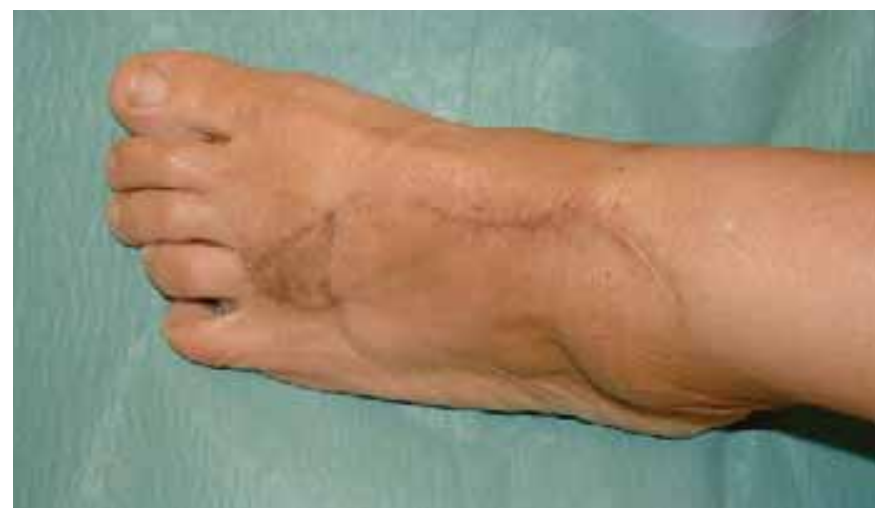

Fig. 10: Resultado postoperatorio a los 6 meses. donantes. Los pacientes reiniciaron la marcha al mes de la intervención. La cobertura cutánea proporcionó suficiente estabilidad. El único dato desfavorable a señalar, es la hipoestesia que suele persistir en el dorso del pie y que puede resultar molesta para algunos pacientes.

\section{Discusión}

Conseguir una cobertura satisfactoria de los defectos de partes blandas de la región distal del pie continúa siendo un problema difícil de resolver. A lo largo de los años se han descrito diversos colgajos locales para la resolución de este problema; entre ellos el colgajo pedio dorsal, un colgajo fasciocutáneo local que requiere del sacrificio de la arteria pedia dorsal lo que limita su uso en casos en los que ha existido un traumatismo previo o en los que el paciente sólo tiene un vaso principal vascularizando el pie. Además este colgajo conlleva una gran morbilidad de la zona donante (10), dificulta la excursión tendinosa y su fiabilidad como colgajo de flujo reverso está en entredicho para algunos autores (11).

Otra opción para la resolución de los defectos distales del pie son los colgajos libres que se utilizan incluso en pacientes diabéticos con buenos resultados. Debido al alto riesgo quirúrgico que supone esta intervención, la necesidad de instrumentación y equipamiento especiales, así como la necesidad de una especial destreza microquirúrgica por parte del cirujano, estos colgajos se reservan para la reconstrucción de grandes defectos. Para los de tamaño mediano optamos por colgajos locales o regionales, siempre que se pueda. Por lo tanto, los colgajos en isla basados en vascularización distal son una buena opción para los defectos distales del pie de tamaño moderado y entre ellos, encontramos el colgajo muscular Extensor Digitorum Brevis.

El colgajo muscular Extensor Digitorum Brevis es un colgajo fiable y seguro que puede usarse de forma pediculada o libre con mínima morbilidad de la zona donante.

Fue descrito en 1979 por McCraw (12) y al principio fue usado como colgajo de flujo proximal para la cobertura de defectos a nivel del tobillo y tercio distal de la pierna (1). Nettelblad y Lidman estudiaron 16 pacientes con defectos del tercio distal de la pierna que solucionaron con colgajo EDB de los cuales sobrevivieron 15 entre los que el problema postoperatorio más común fue la rigidez articular.

Kurata y Soyka (2) describieron el colgajo con flujo retrógrado para la cobertura de los defectos distales del dorso del pie, presentando varias series sobre su uso $(2,6,8,13)$. Hirase y col. (8), así como otros 
autores, han utilizado el colgajo EDB para reconstrucción de heridas del dorso del pie y del tobillo, con mínima morbilidad de la zona donante $(1,2,6,8,14)$. También se tiene experiencia con el colgajo EDB en forma libre para la reanimación facial en casos de parálisis y para la reconstrucción de defectos óseos y de tejidos blandos en traumatismos de mano.

La arteria principal del músculo es la arteria tarsiana lateral (3). La arteria pedia dorsal alcanza el primer espacio intermetatarsiano y da la primera arteria metatarsiana dorsal que se anastomosa con el arco plantar. La base de este colgajo muscular de flujo reverso está en la existencia de anastomosis entre el sistema arterial dorsal y el plantar, por lo que debemos evaluar la $1^{\mathrm{a}}$ arteria metatarsiana dorsal intraoperatoriamente de forma correcta, ya que en algunos casos dicha anastomosis no existe. McCraw, Furlow y Sakai han afirmado que está ausente en un $15 \%$ de los casos. Por tanto, antes de ligar los vasos dorsales proximalmente convendría clamparlos, sólo para ver el flujo distal del colgajo a través de la conexión con el sistema plantar.

Massin y col. (4) describieron una vascularización lateral constante del músculo. Se trata de la arteria perforante peronea que se anastomosa con la arteria tarsiana lateral (4). Por tanto se describe la existencia de un arco vascular lateral del EDB integrado por la arteria perforante peronea y la rama terminal anterior de la arteria peronea. Este arco presenta un calibre adecuado para servir de pedículo del EDB sin interrupción del eje tibial anterior $(4,9)$. Ghareeb $(15)$ usó este pedículo para disecar el colgajo EDB en 14 pacientes para cubrir la zona donante de un colgajo fasciocutáneo pedio dorsal.

En los 2 casos que presentamos, pudimos realizar el colgajo EDB de flujo reverso basado distalmente debido a la existencia de conexión entre el sistema arterial dorsal y el plantar. Tanto en el caso 1 como en el caso 2 el punto pivote fue proximal, a nivel de la articulación tarsometatarsiana. En ninguno de los 2 casos hubo problemas de vascularización arterial ni compromiso de drenaje venoso. Hay que tener en cuenta que el punto pivote proximal existe en todos los casos, sin anomalía anatómica, no así el distal. Si usamos este último, hemos de confirmar la existencia de una vena comitante de la $1^{\text {a }}$ arteria metatarsiana dorsal.

El músculo Extensor Digitorum Brevis se caracteriza por ser poco grueso y abultado, muy útil para la cobertura de tendones y huesos expuestos en el dorso del pie, con un resultado estético aceptable. Recibe su inervación motora a partir de una rama nerviosa del nervio peroneo profundo, que aborda al músculo por su borde medial; tiene una función complementaria y sinérgica con la del extensor largo de los dedos y el extensor largo del dedo gordo, por lo que es prescindible con poca morbilidad funcional (14).

Basando la vascularización del colgajo a nivel distal, con flujo reverso, ganamos un área amplia de cobertura para la parte distal del pie y de los dedos. La condición indispensable para la elevación de un colgajo muscular EDB de flujo distal es la existencia de anastomosis entre el sistema arterial dorsal y el sistema arterial plantar.

Es un colgajo técnicamente fácil de realizar y puede obtenerse en tan sólo una hora.

No requiere instrumentación, equipo especial, ni personal capacitado, por lo que puede ser realizado en la mayoría de los centros quirúrgicos que no disponen de los costosos equipos y del personal necesarios para realizar y supervisar los colgajos libres. Como se trata de un colgajo muscular y no musculocutáneo, la morbilidad de la zona donante es menor, a diferencia del colgajo fasciocutáneo pedio dorsal (10).

Por lo tanto, el colgajo muscular EDB es una buena opción en pacientes con defectos de tobillo y pie que desean una pronta recuperación. En nuestros 2 casos, los pacientes reiniciaron la marcha en torno al mes de la intervención y no presentaron limitación alguna en la extensión de los dedos.

Entre sus desventajas, está la necesidad de colocar un injerto de piel sobre el colgajo muscular y la alteración sensorial en el primer espacio interdigital: la queja principal de nuestros 2 pacientes fue la persistencia de hipoestesia en el dorso del pie. Además no puede realizarse en pacientes con enfermedad vascular periférica o compromiso de circulación en las extremidades. En estos casos el colgajo es poco fiable y presenta una mayor morbilidad de la zona donante.

\section{Conclusiones}

El músculo EDB es un músculo de contorno fino y tamaño suficiente para proporcionar resultados estéticos adecuados en las pérdidas de sustancia del pie de pequeña y mediana dimensión. Su pedículo vascular es largo y relativamente constante, lo que hace que su uso sea muy fiable. Su disección es fácil y la morbilidad de la zona donante mínima. No produce alteración funcional, pues permanece inalterado el músculo extensor largo de los dedos. Ya sea de flujo normal o reverso, el colgajo tiene un arco de rotación grande que permite la cobertura de defectos a nivel del tercio distal de la pierna y del tobillo (a flujo anterógrado), así como de defectos en dorso del pie, dedos e incluso en la región plantar (a flujo retrógrado).

Como desventajas cabe señalar, la necesidad de cobertura complementaria con un autoinjerto de piel y 
la alteración de sensibilidad secundaria en el dorso del pie.

\section{Dirección del autor}

Dra. Consolación de Lope Falcón

C/ Ambrosio de la Cuesta, 9, $4^{\text {a }}$ plta, pta. 32

41014 Sevilla. España.

e-mail: conso.delope@telefonica.net

\section{Bibliografía}

1. Landi A., Soragni O., Monteleone M.: "The extensor digitorum brevis muscle island flap for soft-tissue loss around the ankle". Plast.Reconstr.Surg.1985;75: 892.

2. Kurata S., Hashimoto H., Terashi H., Honda T., Takayasu S.: "Reconstruction of the distal foot dorsum with a distally based extensor digitorum brevis muscle flap". Ann. Plast. Surg.1992;29:76.

3. Del Piñal F., Herrero F.: "Extensor Digitorum Brevis Fee Flap: Anatomic Study and Further Clinical Applications". Plast. Reconstr. Surg. 2000;105 (4): 1347

4. Massin, Ph., Romana, C., and Masquelet, A. C.: "Anatomic basis of a pediculed extensor digitorum brevis muscle flap". Surg. Radiol. Anat. 1988;10:267.

5. Gilbert A.: "Composite Tissue Transfers from the Foot: Anatomic Basis and Surgical Technique". In A. J. Daniller and B. Strauch
(Eds.), Symposium on Microsurgery. St. Louis: Mosby,1976. Pp.230-241.

6. Bakhach J., Demiri E., Chahidi N., Baudet J.: "Extensor digitorum brevis muscle flap: New refinaments". Plast. Reconstr. Surg.1998;102(1):103.

7. Belmahi A., Fejjal N., Gharib N-E., EI Mazouz S.: "Le lambeau du muscle court extenseur des orteils à flux rètrograde au secours des pertes de substance disteles du pied. À propos de six cas".Ann Chir Plast Esthét. 2005;50:282.

8. Hirase, Y., Kojima, T., Fukumoto, k., Misu, H., Yamaguchi, T. "Indication and practice of reverse flow extensor digitorum brevis muscle flap transfer". Ann Plast Surg.2003;51(3):273.

9. Ger, R.: "Extensor digitorum brevis muscle flap". In B. Strauch, L. O. Vasconez, and E. J. Hall-Findlay (Eds.), Grabb's Encyclopedia of Flaps, 2nd Ed. Philadelphia: Lippincott- Raven,1998.Pp.1891.

10. Samson MC., Morris SF., Tweed AE.: "Dorsalis pedis flap donor site: acceptable or not?". Plast Reconstr Surg.1998;102:1549.

11. Touam C., Rostoucher P., Bhatia A., et al.: "Comparative study of two series of distally based fasciocutaneous flaps for coverage of the lower one fourth of the leg, the ankle, and the foot". Plast Reconstr Surg.2001;107:383.

12. McCraw JB.: "Selection of alternative local flaps in the leg and foot". Clin Plast Surg.1979;6:227.

13. Gibstein LA., Abramson DL., Sampson CE., et al.: "Musculofascial flaps based on the dorsalis pedis vascular pedicle for coverage of the foot and ankle". Ann Plast Surg. 1996;37:152.

14. Giordano PA., Argenson C., Pequignot JP.: "Extensor digitorum brevis as an island flap in the reconstruction of soft tissue defects in the lower limb". Plast Reconstr Surg. 1989; 83:100.

15. Ghareeb FM.: "Using the extensor digitorum brevis muscle to improve donor site morbidity of the dorsalis pedis flap". Plast Reconstr Surg.2002;109:2031. 


\title{
Comentario al trabajo "Empleo del colgajo muscular extensor digitorum brevis con flujo retrógrado para defectos distales en el pie
}

\author{
Dr. Francisco del Piñal \\ Cirujano Plástico. Práctica privada, Mutua Montañesa. Santander. España
}

Los autores presentan el uso de dos colgajos de músculo pedio de flujo retrógrado para cobertura de defectos en el antepié en 2 pacientes, sin ninguna complicación. Estoy de acuerdo con los autores en que el colgajo pedio es un buen colgajo. No obstante, en contra de la experiencia feliz de los autores hemos tenido problemas vasculares mayores que han requerido cirugía "capacitada" para solventarlos (no me parece bien considerar sólo cirugía capacitada a la microcirugía, pero eso dicen ellos en el texto). He revisado para esta discusión nuestra experiencia: hemos hecho 32 músculos pedios (parte libres, parte pediculados) pero puede ser que tengamos alguno más, ya que no ha sido una búsqueda en profundidad, sino sólo para tener una idea general de de qué estábamos hablando. De todos esos sólo recuerdo uno que se necrosara (encima pediculado!!!) en un paciente con una neuropatía periférica. Esto me cogió joven y no entendí muy bien por qué había ocurrido si no habíamos dañado ninguna estructura. Con posterioridad hemos tenido 3 casos más con problemas vasculares (perfusión 0 al soltar el manguito con el músculo aún pediculado) y en todos ellos encontramos una buena arteria pedia con una arteria tarsiana lateral reemplazada por tejido fibrótico ( $\sin$ trauma previo), y con venas concomitantes sanas. Por alguna razón que se me escapa la arteria tarsiana lateral tiene una tendencia a la obstrucción y al endurecimiento, posiblemente por hiperplasia de la íntima como ocurre en la arteria comunicante distal en los dedos del pie (1). Estos músculos pedios están irrigados en sentido lateral a medial (desde la arcada lateral dependiente de la calcánea lateral y de una rama externa de la plantar lateral). La única manera de salvarlos es hacer un pontaje desde la pedia a la arteria tarsiana lateral pero ya en la rama del seno del tarso....y eso es una fiesta para un microcirujano experto: las arterias son como papel de fumar, la íntima es como baba y hay una discrepancia de calibre tremenda entre el injerto y la receptora (Fig. 1). En otro caso reperfundimos pediculando la arteria tarsiana látero-distal y suturándola a la del seno del tarso. En el último caso, al ver que el pedículo estaba fibrótico, preservamos la vascularización de la arcada lateral, y de ahí lo rotamos para cubrir el defecto, que afortunadamente era lateral, sin más complicaciones. En el caso de que el colgajo se haya elevado como libre hay que anastomosar la arteria lateral en lugar de medial.

Los autores aseguran que la anatomía vascular proximal es constante. La experiencia clínica nos ha mostrado de nuevo que esto no es así y hemos tenido algún "problemilla", que ha requerido cirugía de sufrimiento para solventarlo. Cuando la arteria tibial anterior es hipoplásica, en un 5\% de los casos (2), entonces es reemplazada por una perforante de la peronea. El recorrido de esta arteria es algo más lateral, y eso hace que la arteria tarsiana lateral sea menor (3), a veces no existe, como en la Fig. 2. Aunque esta variación no presenta un problema infranqueable para el caso de un colgajo de flujo retrógrado, salvo que el pedículo efectivo es bastante más corto, para todas las demás formas de utilizar este colgajo lo es, y grande.

Elevamos el colgajo siguiendo la técnica que describimos en el 2000 (3), ya que es muy rápida y uno se asegura de que no va a dañar la arteria dominante del músculo. La clave es localizar la arteria tarsiana lateral en su origen, en la vecindad de la interlínea tibio-astragalina (el retináculo como referencia es muy poco fiable). Disecamos este pedículo lo más lateral que podemos, debajo del músculo. Una vez aislado el pedículo, el resto de la disección se hace de forma rápida coagulando ( $\sin$ miramientos) todas las ramas menores que hay, hasta llegar a la vecindad de la arteria tarsiana lateral, donde encontraremos una rama constante que va al seno del tarso. Sólo esta rama plantea problemas para ligarla, ya que es corta y adherida al periostio, y si se tracciona se puede dañar la vascularización del músculo propiamente dicha. Siguiendo este método, se puede elevar el colgajo en 15-20 minutos en un pie sano, pero en uno traumatiza-

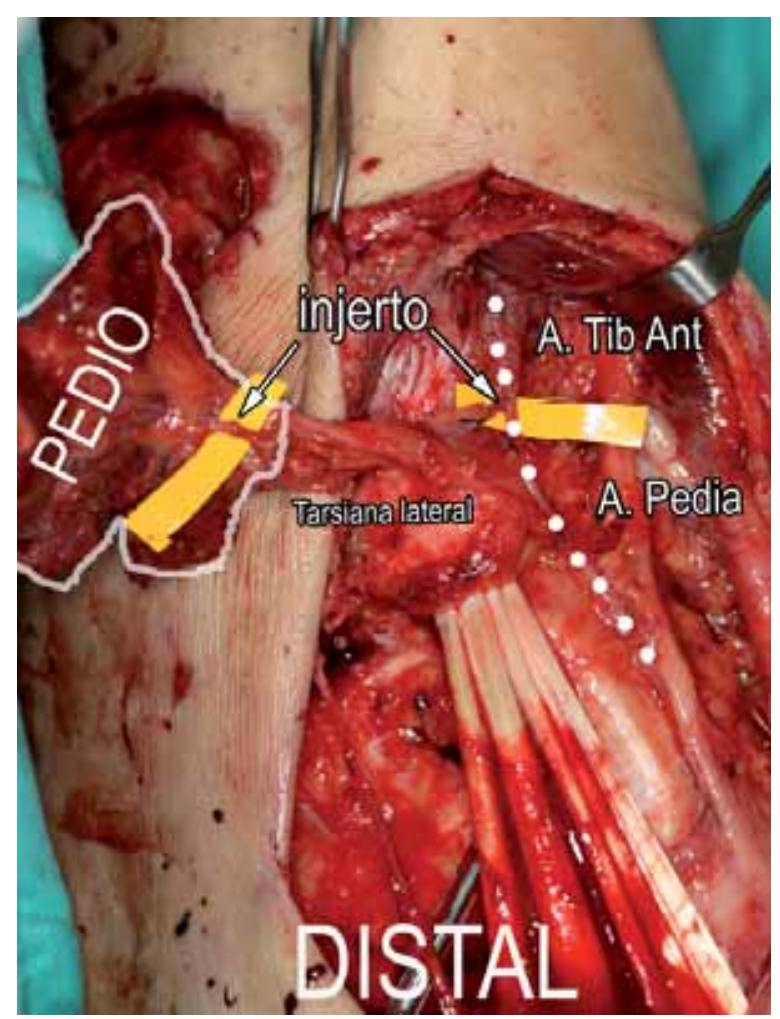

Fig. 1.

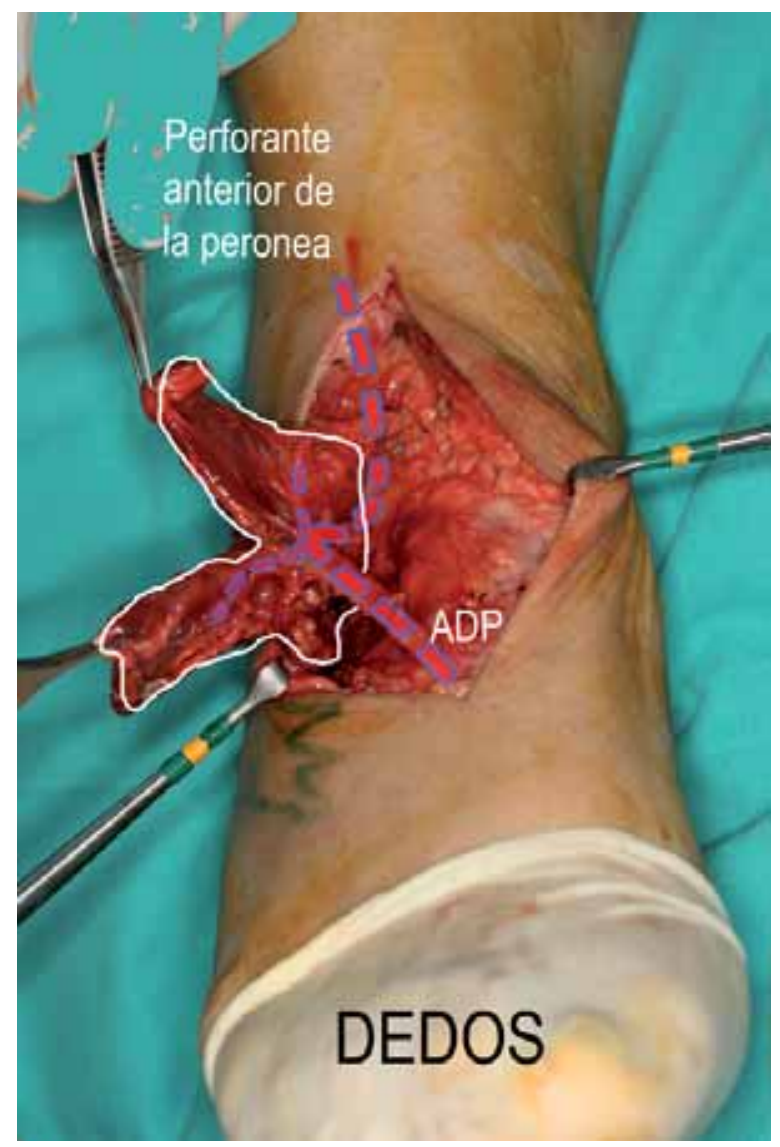

Fig. 2. 


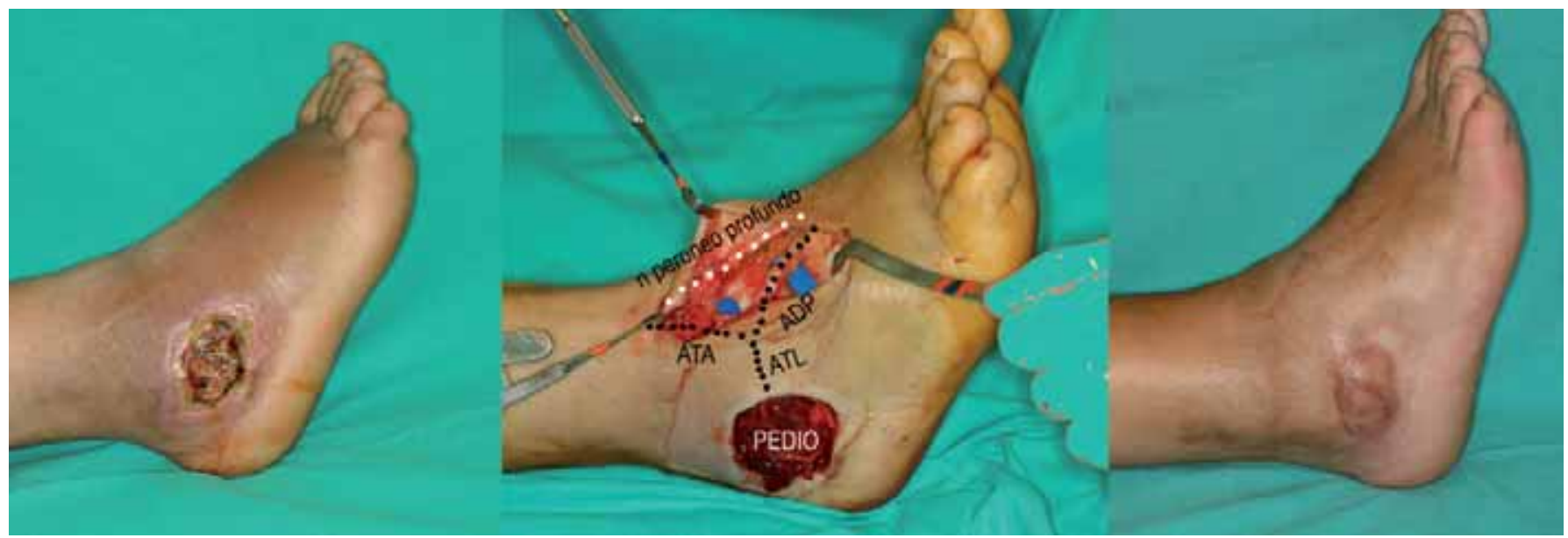

Fig. 3.

do, en especial si hubo un aplastamiento, la disección puede ser mucho más difícil: el pedículo está envuelto en fibrosis, y las venas se rasgan con facilidad y se rompen a la mínima tracción. O sea, que también puede ser un martirio la disección en esos casos.

Los autores no hablan del drenaje venoso, que en la variante de colgajo que ellos presentan debe ser contra las válvulas. En algún caso que he realizado de músculo pedio de flujo retrógrado (pecadillos de juventud) he tenido congestión en el músculo y se ha perdido parcialmente el injerto. Parece prudente esperar unos días a que el músculo se estabilice y luego poner con anestesia local el injerto...o ponerlo en planta como una cura. Esto no debe sorprender ya que particularmente en las venas de la pierna hay tal cantidad de válvulas que sólo con pedículos muy cortos puede la sangre venosa tener un retorno retrógrado libre de obstáculos (4).

Me da miedo, después de todo lo dicho que alguien pueda pensar que el músculo pedio es un mal colgajo, que no lo es, lo que ocurre es que según uno va empleándolo y forzando su indicación, aparecen los problemas que crees que a ti nunca te van a pasar...y cuando estás inmerso en uno de ellos (además de acordarte de quien había dicho que el pedio era un colgajo fácil y seguro) sí que hace falta recurrir a todas las armas que tiene un microcirujano muy capacitado (aquí sí estoy de acuerdo en que hay que estar capacitado) si no quieres añadirte otra marca negra más en tus zuecos. El músculo pedio está dónde más hace falta y aunque por su tamaño sólo puede cubrir defectos pequeños, no por serlo dejan de ser un gran problema (decía mi jefe Ian Taylor que los "agujeros" no eran ni grandes ni pequeños, eran complejos o no). Una de las formas más sencillas y menos agresiva de cubrir defectos en la región retromaleolar es la variante que llamamos "pedio en arco" (que yo sepa no está publicado). Este concepto del arco, que se puede aplicar en cualquier otro colgajo, consiste en seccionar todas las ramas del eje arterial principal en un determinado trayecto, de tal forma que se moviliza en bloque hacia la dirección deseada el colgajo, su pedículo, y el eje arterio-venoso principal. La longitud efectiva del pedículo del colgajo aumenta considerablemente y con esta simple maniobra se consigue cubrir defectos "imposibles" (Fig. 3).

En resumen, que felicito a los autores por traer el músculo pedio otra vez a la palestra.... un buen colgajo que a veces no se tiene en mente para solventar defectos pequeños en el pie.

\section{Bibliografía}

1. del Piñal F, García-Bernal FJ, Ayala H, Cagigal L, Regalado J, Studer A.: "Ischemic toe encountered during harvesting: report of 6 cases". J Hand Surg [Am]. 2008, 33(10):1820.

2. Cormack, G. C., and Lamberty, B. G. Lower Leg.: In G. C. Cormack and B. G. Lamberty (Eds.), "The Arterial Anatomy of Skin Flaps", 2nd Ed. Edinburgh: Churchill Livingstone, 1994. Pp. 248-257.

3. Piñal F del, Herrero F.: "Extensor digitorum brevis free flap: anatomic study and further clinical applications". Plast Reconstr Surg. 2000, 105(4):1347.

4. Pinal F del, Taylor GI.: "The deep venous system and reverse flow flaps”. Br J Plast Surg. 1993,46(8):652.

\section{Respuesta al comentario del Dr. del Piñal}

\section{Dra. De Lope Falcón}

En primer lugar agradecer al Dr. del Piñal sus, como siempre, excelentes comentarios y sugerencias. Como en toda luna de miel todo va sobre ruedas al principio y es con el paso de los años cuando hay que hacer frente a los problemas. Es obvio que su experiencia hace encojerse a quienes iniciamos nuestra andadura en este tipo de intervenciones, así que tenemos poco que decir y mucho que aprender. Pero como cualquier cosa que comienza con ilusión, la necesidad de comunicarlo al resto de profesionales en un intento de ayudar a mejorar el quehacer diario es dificilmente contenible. Estamos de acuerdo en opinar que el cogajo EDB es una buena opción en aquellos pequeños defectos del pie y también en que debemos estar preparados para cualquier problemilla que pueda surgir. De momento, en estos dos casos presentados, todo fue sencillo y rápido de realizar (suerte del principiante). En ninguno de los dos hubo traumatis- mo previo ni enfermedad vascular de base, lo que probablemente contribuyó al éxito de sendas intervenciones. No necesitamos ninguna maniobra especial para mejorar la vascularización del colgajo ya que fue bastante buena, sin variación anatómica y con una arteria tarsiana lateral perfecta. No tuvimos problemas de retorno venoso en el postoperatorio e injertamos el colgajo en el mismo tiempo quirúrgico con éxito. Sin lugar a dudas si tuviéramos un mayor número de casos podríamos encontrarnos con los problemas a los que se ha ido enfrentando en su larga trayectoria el Dr. del Piñal y de los cuales ha ido aprendiendo y enseñando a los demás. Y para concluir, decir, que a pesar de los inconvenientes que puedan surgir a la hora de realizar este colgajo, si que deberíamos tenerlo cada vez más en cuenta, sobre todo en estos casos donde es difícil plantear una buena cobertura,y sobre todo estar lo suficientemente preparados para afrontarlos. 